\title{
From bacteria to plants: a repurposing strategy in the pursuit for novel herbicides
}

Short title: Herbicidal inhibitors with a novel mode of action

Emily R. R. Mackie ${ }^{1,2}$, Andrew S. Barrow ${ }^{1}$, Marie-Claire Giel ${ }^{1}$, Mark D. Hulett ${ }^{1}$, Anthony R. Gendall $^{3,4}$, Santosh Panjikar ${ }^{5,6}$ and Tatiana P. Soares da Costa ${ }^{1,2, *}$

${ }^{1}$ La Trobe Institute for Molecular Science, La Trobe University, Bundoora, VIC 3086, Australia

${ }^{2}$ School of Agriculture, Food and Wine \& Waite Research Institute, University of Adelaide, Waite Campus, Glen Osmond, SA 5064, Australia

3 Australian Research Council Industrial Transformation Research Hub for Medicinal Agriculture, AgriBio, La Trobe University, Bundoora, VIC 3086, Australia

${ }^{4}$ Department of Animal, Plant and Soil Sciences, La Trobe University, Bundoora, VIC 3086, Australia

${ }^{5}$ Australian Synchrotron, ANSTO, 800 Blackburn Road, Clayton, VIC 3168, Australia

${ }^{6}$ Department of Molecular Biology and Biochemistry, Monash University, Melbourne, VIC 3800, Australia

*Corresponding author:

T. P. Soares da Costa

Address: School of Agriculture, Food and Wine \& Waite Research Institute, University of Adelaide, Waite Campus, Glen Osmond, SA 5064, Australia

E-mail: tatiana.soaresdacosta@adelaide.edu.au 


\begin{abstract}
Herbicide resistance represents one of the biggest threats to our natural environment and agricultural sector. Thus, new herbicides are urgently needed to tackle the rise in herbicideresistant weeds. Here, we employed a novel strategy to repurpose a 'failed' antibiotic into a new and target-specific herbicidal compound. Specifically, we identified an inhibitor of bacterial dihydrodipicolinate reductase (DHDPR), an enzyme involved in lysine biosynthesis in plants and bacteria, that exhibited no antibacterial activity but severely attenuated germination of the plant Arabidopsis thaliana. We confirmed that the inhibitor targets plant DHDPR orthologues in vitro, and exhibits no toxic effects against human cell lines. A series of analogues were then synthesised with improved efficacy in germination assays and against soil-grown $A$. thaliana plants. We also showed that our lead compound is the first lysine biosynthesis inhibitor with herbicidal activity against a weed species, providing proof-of-concept that DHDPR inhibition may represent a much-needed new herbicide mode of action. Furthermore, this study exemplifies the untapped potential of repurposing 'failed' antibiotic scaffolds to fast-track the development of herbicide candidates targeting the respective plant enzymes to combat the global rise in herbicide-resistant weeds.
\end{abstract}


bioRxiv preprint doi: https://doi.org/10.1101/2022.02.20.481218; this version posted February 21, 2022. The copyright holder for this preprint (which was not certified by peer review) is the author/funder, who has granted bioRxiv a license to display the preprint in perpetuity. It is made available under aCC-BY-NC-ND 4.0 International license. 
Herbicides play an integral role in modern agricultural practices as they enable the cost-effective management of weeds. ${ }^{1}$ However, herbicide options are dwindling due to the rapid emergence and spread of herbicide-resistant weed populations. Such weeds aggressively compete with crops for resources, resulting in decreased harvest yields and quality. The diminishing efficacy of current herbicides, coupled with the lack of new herbicides with novel modes of action over the last 30 years, has prompted serious concerns over sustainable agriculture. ${ }^{2,3}$ Consequently, there is an urgent need for the development of new herbicides, especially those with new modes of action.

The biosynthetic pathways that lead to the production of amino acids in plants have long been targeted for herbicide discovery, with great commercial success. ${ }^{4}$ The most widely used herbicide, glyphosate (the active ingredient in Roundup®), targets the production of aromatic amino acids through inhibition of the enzyme 5-enolpyruvyl-shikimate 3-phosphate synthase (EPSPS, EC 2.5.1.19). ${ }^{4}$ Similarly, herbicides that inhibit the biosynthesis of glutamine (e.g. glufosinate) and branched chain amino acids (e.g. chlorsulfuron) target a single enzyme within each pathway and have become indispensable to agricultural industries. ${ }^{4}$ Underpinning the success of these herbicides is the essentiality of amino acids for physiological processes, including protein synthesis, carbon and nitrogen metabolism, and the production of secondary metabolites. ${ }^{5}$ Given that plants can synthesise all amino acids, arresting their production represents an excellent herbicide development strategy. As such, we proposed that the unexplored diaminopimelate (DAP) pathway, which is responsible for lysine biosynthesis exclusively in plants, bacteria and algae, represents a potential herbicide target (Figure 1)., Furthermore, we have recently identified the first lysine biosynthesis inhibitors with herbicidal activity against the model plant Arabidopsis thaliana, which target the first enzyme in the DAP pathway, dihydrodipicolinate synthase (DHDPS, EC 4.3.3.7) (Figure 1). ${ }^{7-9}$

Despite the potential of targeting lysine biosynthesis production in plants as a strategy for herbicide development, little research has been done to date. Conversely, over the past 30 years many studies have focused on the development of antibiotics by inhibiting bacterial lysine biosynthesis enzymes. ${ }^{10-16}$ However, in vitro inhibitors of the bacterial enzymes are not effective against intact pathogenic bacteria, and hence, they have not progressed through the antibiotic 
development pipeline. ${ }^{10,13}$ These compounds are typically small molecules with $\mathrm{MW}<350 \mathrm{~g}^{\cdot \mathrm{mol}^{-}}$ 1 , the size of nearly all commercial herbicides to date. Moreover, plant enzymes in the DAP pathway are closely related to the bacterial orthologues and are essential for plant survival. ${ }^{7,17,18}$ Given the high degree of similarity between these enzymes from bacteria and plants, we explored the possibility that these 'failed' antibiotics could be repurposed into inhibitors of the respective plant enzymes. This strategy would circumvent the laborious screening of chemical libraries with unknown targets typically used in herbicide discovery, and therefore provide a fasttracked method to develop urgently needed novel herbicide modes of action.

This study focuses on the second enzyme in the DAP pathway, dihydrodipicolinate reductase (DHDPR, EC 1.17.1.8) (Figure 1). Although there are no published plant DHDPR inhibitors, there are examples of inhibitors of the bacterial orthologues. ${ }^{10,19}$ The most well-characterised is 2,6-pyridine dicarboxylic acid (2,6-PDC), which has mid-micromolar potency against several bacterial DHDPR enzymes, including that from Escherichia coli (Ec), but with no antibacterial activity reported. ${ }^{10,19}$ Upon the recent publication of the first plant DHDPR structure, we postulated that 2,6-PDC may also bind to and inhibit plant DHDPR enzymes. ${ }^{20}$

Here, we sought to explore the evolutionary relationship between bacterial and plant DHDPR enzymes to repurpose 2,6-PDC as a potential herbicidal scaffold. To achieve this, we recombinantly produced two DHDPR enzymes from A. thaliana, AtDHDPR1 and AtDHDPR2. Subsequently, we characterised AtDHDPR1 functionally and structurally using enzyme kinetics assays and X-ray crystallography, and compared it to the previously characterised AtDHDPR2 and EcDHDPR enzymes. We confirmed that 2,6-PDC displays micromolar inhibition against AtDHDPR1 and AtDHDPR2 in vitro using enzyme kinetics assays, and is able to inhibit the germination of $A$. thaliana plants. To confirm its specificity, we employed antibacterial and cytotoxicity assays and determined that 2,6-PDC lacks activity against soil microbes and human cells. Finally, a series of analogues of 2,6-PDC were synthesised that had improved potency in germination assays, and when applied to soil-grown plants. Importantly, our lead inhibitor displayed herbicidal activity against the invasive weed species rigid ryegrass (Lolium rigidum). 


\section{RESULTS}

\section{Production of recombinant AtDHDPR proteins}

The AtDHDPR1-encoding gene At2G44040 was identified using The Arabidopsis Information Resource (TAIR, https://www.arabidopsis.org/) and the resulting protein sequence uploaded to the ChloroP server for identification of the chloroplast transit peptide (cTP). ChloroP predicted a cTP length of 53 amino acids, however the final two amino acids were excluded based on the sequence of the previously characterised AtDHDPR2. Thus, the final construct was designed to exclude the first 51 amino acids and incorporate a custom fusion tag (Met- $6 \times$ His-3C protease recognition site) for purification by immobilised metal affinity chromatography (IMAC) and tag removal (Supplementary Figure 1). A similar strategy was used to produce AtDHDPR2. The protein sequence resulting from the AtDHDPR2-encoding gene At3G59890 was used to predict a cTP length of 53 amino acids, which were excluded from the construct. Subsequent CD spectroscopy analysis revealed a similar secondary structure composition of $51 \%$ and $59 \% \alpha / \beta$ structure for AtDHDPR1 and AtDHDPR2, respectively (Supplementary Figure S2). These results are in agreement with previous studies of bacterial and cyanobacterial orthologues, indicating correct protein folding. ${ }^{21,22}$

\section{Catalytic activity of AtDHDPR1}

Having determined that AtDHDPR1 is folded similarly to AtDHDPR2, the kinetic properties of the enzyme were determined using a well-established DHDPS-DHDPR coupled assay. ${ }^{23}$ The best fits were obtained with a substrate inhibition model, consistent with inhibition by DHDP when using NADPH as the cofactor, which has been reported for AtDHDPR2 and other orthologues (Figure 2). ${ }^{20,22,24}$ AtDHDPR1 has a $k_{\text {cat }}$ of $27 \mathrm{~s}^{-1}, K_{\mathrm{M}}(\mathrm{DHDP})$ of $37 \pm 6.5 \mu \mathrm{M}$ and $K_{\mathrm{M}}(\mathrm{NADPH})$ of $16 \pm 2.6 \mu \mathrm{M}$. These kinetic constants are similar to the previously reported values for AtDHDPR2 of a $K_{\mathrm{M}}(\mathrm{DHDP})$ of $57 \mu \mathrm{M}$ and $K_{\mathrm{M}}(\mathrm{NADPH})$ of $35 \mu \mathrm{M}^{24}$

\section{Structural determination of AtDHDPR1 and comparison with AtDHDPR2 isoform}

Given that plants generally possess two DHDPR isoforms, we investigated the similarity between paralogous plant DHDPR isoforms by determining the crystal structure of AtDHDPR1 and comparing it to the previously characterised AtDHDPR2 structure (PDB ID: 5UA0). The AtDHDPR1 structure has an N-terminal Rossmann-fold that is typically observed in DHDPR 
enzymes and a C-terminal oligomerisation domain that differs between species. ${ }^{17}$ AtDHDPR1 was crystallised as a monomer in the asymmetric unit, however based on symmetry operations was predicted to assemble as a weak tetramer, or 'dimer of dimers,' with a tight dimerisation interface. This is consistent with analytical ultracentrifugation analyses, which show that AtDHDPR1 exists in a dimer-tetramer equilibrium in solution (Supplementary Figure S3). As has been observed for AtDHDPR2, AtDHDPR1 was crystallised with the 'latch and catch' residues Met146, Gln145 and Thr189 within hydrogen bonding proximity (Figure 3). ${ }^{17}$ Interactions between these residues stabilise the enzyme's closed conformation by pulling the Nterminal domain towards the C-terminal domain. ${ }^{17}$

Interestingly, the AtDHDPR1 structure lacked density for a nearly identical set of active site residues to those that could not be modelled in chain B of the AtDHDPR2 structure. The substrate binding loop within which these residues are contained is highly flexible, which may explain the disorder observed in this region. Indeed, such flexibility is supported by the inhibition of AtDHDPR1 by its substrate that was observed here, which has been reported to be a consequence of increased flexibility in this region in the plant enzymes. ${ }^{17}$ A structural alignment of AtDHDPR1 and AtDHDPR2 resulted in an RMSD of $0.5 \AA$ over 1741 equivalent atoms, indicating a high degree of structural similarity (Figure 3).

\section{Sequence and structural homology of the 2,6-PDC binding pocket}

The previously determined crystal structure of EcDHDPR in complex with 2,6-PDC (PDB ID: 1ARZ) showed a hydrogen bond network encompassing five active site residues that are conserved across bacterial species (Figure 4A). ${ }^{25}$ An alignment of the EcDHDPR amino acid sequence with that of both AtDHDPR isoforms revealed that four of the five residues involved in 2,6-PDC binding are conserved (Figure 4B). EcDHDPR and AtDHDPR1 resulted in an RMSD of $6.2 \AA$ for 1193 equivalent carbon atoms, whereas an RMSD of $3.5 \AA$ for 1276 equivalent carbon atoms was revealed when EcDHDPR was overlaid with AtDHDPR2. Inspection of the residues involved in 2,6-PDC binding indicates a structurally conserved binding pocket that may accommodate 2,6-PDC binding to AtDHDPR enzymes (Figure 4C). 


\section{Suitability of 2,6-PDC as a plant DHDPR inhibitor scaffold}

The potency of 2,6-PDC against both AtDHDPR isoforms was assessed using the DHDPSDHDPR coupled assay, with substrates fixed at their respective $K_{\mathrm{M}}$ values. 2,6-PDC inhibited AtDHDPR1 with an $I C_{50}$ of $140 \mu \mathrm{M}$ and AtDHDPR2 with an $I C_{50}$ of $470 \mu \mathrm{M}$. Therefore, 2,6PDC represents the first example of a plant DHDPR inhibitor and a potential scaffold for the synthesis of more potent analogues. To assess whether 2,6-PDC had activity against plants, A. thaliana seeds were raised on media containing a concentration gradient of inhibitor (Figure 5A). The herbicidal activity of 2,6-PDC was visually evident from a near complete inhibition of growth above a concentration of $2 \mathrm{mM}$, and reduced growth at $1 \mathrm{mM}$. Quantitative analysis of the plant growth area at each concentration enabled the generation of a dose response curve from which an $\mathrm{LD}_{50}$ of $1.1 \mathrm{mM}$ was determined (Figure $\left.5 \mathrm{~B}\right) .{ }^{26}$ Given that 2,6-PDC is an inhibitor of bacterial DHDPR enzymes, we employed antibacterial assays to examine its selectivity. The compound had no activity against bacterial strains commonly found in soil, with MIC values >5 mM (Supplementary Table S1). We further investigated the specificity of 2,6PDC using a cell viability assay, which demonstrated that it lacks off-target toxicity against the human cell line, HepG2, with no significant difference in viability observed between control and treatment groups up to $5 \mathrm{mM}$ (Supplementary Figure S4). The specificity for plants over common soil flora and human cells suggested that 2,6-PDC could be a suitable scaffold to pursue for the development of herbicidal DHDPR inhibitors.

\section{Synthesis and structure-activity relationship of 2,6-PDC analogues}

To afford insight into the chemical features important for 2,6-PDC potency, a series of analogues were synthesised. In total, 21 analogues were prepared, incorporating amide, ester and aldehyde functionality centred around a 2,6-disubstitued pyridine core (Supplementary Methods S1 and Supplementary Data S1). Analogues were screened for herbicidal activity at a concentration of $1 \mathrm{mM}\left(\sim \mathrm{LD}_{50}\right.$ for parent) against $A$. thaliana seeds grown on agar (Table 2). The amide analogues (1-7) generally displayed reduced activity compared to 2,6-PDC. Of the linear chain esters (8-13), those with a carbon chain length of 3 and $4(\mathbf{1 0}, \mathbf{1 1})$ were more active than 2,6PDC. Incorporation of a terminal halide $(\mathbf{1 4}, \mathbf{1 5})$ or alkynyl functionality $(\mathbf{1 6}, \mathbf{1 7})$ in the carbon chain also improved the activity, although was not as beneficial as the equivalent unsubstituted carbon chain length $(\mathbf{1 0}, \mathbf{1 1})$. However, modification of the shorter carbon chain length 
analogues $(\mathbf{8}, \mathbf{9})$ through the addition of the electron-withdrawing $\mathrm{CF}_{3}$ moiety $(\mathbf{1 8})$ or a branched carbon chain (19) afforded improvements relative to analogues 8 and $\mathbf{9}$. Conversely, the 3methoxy substituted analogue $\mathbf{2 0}$ had slightly reduced activity compared to the unsubstituted equivalent (11). The benefits of modification of the carboxylic acid moiety to the corresponding aldehyde (21) were comparable to analogues 10 and 11. Those exhibiting the best activity, that is, those that arrested growth upon radicle emergence or prevented seed germination entirely, had a carbon chain length of 2 if halide-substituted $(\mathbf{1 4}, \mathbf{1 5})$, or 3-4 if unsubstituted $(\mathbf{1 0}, \mathbf{1 1})$, with the exception of the aldehyde (21).

\section{Herbicidal efficacy of 2,6-PDC analogues}

The most promising inhibitors identified from the agar assays described above were screened for herbicidal activity against soil-grown plants alongside 2,6-PDC (Figure 6). In contrast to the growth inhibition studies conducted on media (Table 2), the clear distinction between the effects of analogues on soil-grown $A$. thaliana allowed us to identify four lead compounds $(\mathbf{1 4}, \mathbf{1 5}, \mathbf{1 6}$, 17). The halide substituted analogues $(\mathbf{1 4}, \mathbf{1 5})$ largely prevented seed germination, and for those that did germinate, growth was greatly impaired (Figure 6). Interestingly, the terminal alkynyl functionality $(\mathbf{1 6}, \mathbf{1 7})$ was the most beneficial, more so than the saturated carbon chain of equivalent length $(\mathbf{1 0}, \mathbf{1 1})$ (Figure 6). Of the two alkynes, the shorter carbon chain (16) was more effective at preventing germination (Figure 6). To assess whether the herbicidal efficacy observed against $A$. thaliana could extend to other species, the invasive weed species $L$. rigidum was treated with 16 (Figure 7). Treatment with $1200 \mathrm{mg} \cdot \mathrm{L}^{-1}$ (equivalent to $48 \mathrm{~kg} \cdot \mathrm{ha}{ }^{-1}$ ) of 16 successfully inhibited germination and growth, albeit it with reduced potency than against $A$. thaliana, with treated plants having a significantly reduced fresh weight of shoots and roots compared to the vehicle control (Figure 7A-B). A significant reduction in shoot dry weight was also observed (Figure 7C). This compound represents the first example of a lysine biosynthesis pathway inhibitor with herbicidal activity against a weed species.

\section{DISCUSSION}

The inhibition of amino acid biosynthesis in plants has been a historically successful herbicide development strategy. However, examples of herbicidal lysine biosynthesis inhibitors had not been identified until our recent study reporting the first class of such inhibitors, which target the 
DHDPS enzyme. ${ }^{7}$ Subsequently, we set out to explore the next enzyme in the lysine biosynthesis pathway, DHDPR, as a potential herbicide target. Compared to amino acid biosynthesis enzymes targeted by commercial herbicides, the maximal expression levels of both AtDHDPR isoforms are comparable or lower, suggesting that achieving phytotoxicity with DHDPR inhibitors should not be hindered by high levels of target expression (Supplementary Table S2). ${ }^{27}$ Although no inhibitors of plant DHDPR enzymes have been reported previously, 2,6-PDC has been identified as an inhibitor of bacterial DHDPR orthologues, and thus, the present study aimed to assess the potential to repurpose the 2,6-PDC scaffold as a herbicide candidate.

Comparison of the primary sequences and crystal structures of bacterial and plant DHDPR orthologues revealed a high degree of conservation at the 2,6-PDC binding site, suggesting that this compound may also inhibit plant enzymes. Enzyme inhibition and plant germination assays supported our hypothesis. The presence of DHDPR in bacteria means that potential disruption of beneficial soil microbe communities needs to be addressed in the design of herbicidal DHDPR inhibitors. Despite 2,6-PDC being an in vitro inhibitor of bacterial DHDPR, the lack of antibacterial activity suggests that plant-specific inhibitors can be developed. Indeed, efflux and poor uptake of compounds by bacteria, which can impede the development of antibacterial agents, may conversely be an advantage in repurposing them as specific herbicides. ${ }^{28-30}$ Our findings that 2,6-PDC inhibited the germination of plants with specificity over bacterial and human cells prompted the subsequent synthesis of 21 analogues of 2,6-PDC, some of which had improved potency in a plant germination screen. Subsequent in-soil testing revealed that some of the analogues, which appeared promising in the screening phase, had reduced activity against soil-grown A. thaliana. This may be attributed to a complex range of factors influencing herbicidal activity. For example, compounds with good activity against the enzyme target may not necessarily have good soil binding properties, or resistance to clearance by the plant or soil flora. Whilst testing on plants in soil is important to assess these factors, initial screening of compounds in media provides an efficient strategy to rule out compounds lacking activity. Moreover, four of the analogues almost completely inhibited A. thaliana germination on soil, at a dose within one order of magnitude of conventional application rates of commercial herbicides such as asulam and atrazine. 
Treatment of the invasive species $L$. rigidum with the most promising inhibitor $\mathbf{1 6}$ resulted in significant inhibition of its growth, suggesting that DHDPR inhibitors have the potential to be developed into herbicide candidates. However, the reduced potency of $\mathbf{1 6}$ against L. rigidum compared to $A$. thaliana instantiates the long road from lead identification to commercial formulation. Optimisation of the physicochemical properties of herbicide leads has the potential to improve soil persistence, delivery into the plant and leaf uptake for potential post-emergence application (Supplementary Table S3). For example, increasing the lipophilicity of these compounds would likely increase their translocation across the cuticle, cell wall and cell membrane. Furthermore, the high degree of conservation of DHDPR enzymes across plant species suggests that the specificity of these compounds for weeds is unlikely (Supplementary Figure S5). ${ }^{31}$ Directed evolution experiments would therefore be of interest to identify mutations which may be used to engineer crops resistant to DHDPR active site inhibitors. Identifying such mutations would also facilitate the monitoring of weed populations for the emergence of resistance so that early intervention strategies may be implemented.

Repurposing inhibitor scaffolds, as we have exemplified here, has the potential to fast-track herbicide discovery given that lead identification often involves costly high-throughput screening, or time-consuming rational design. ${ }^{32}$ Indeed, drug repurposing efforts have recently uncovered the herbicidal efficacy of the antibiotic ciprofloxacin, as well as antimalarial lead compounds. ${ }^{33,34}$ However, these drugs could not be used as herbicides due to the risk of accelerating the development of resistance to important medicines, without modifications to improve plant specificity. This drawback may be overcome by repurposing scaffolds that have not progressed through the drug development pipeline, such as 2,6-PDC. This study paves the way for future research into repurposing scaffolds previously identified as inhibitors of bacterial targets that have a high degree of similarity to enzymes in the plant kingdom. Given the rapidly increasing rate of herbicide resistance, such scaffolds could represent novel molecules for the development of much-needed new herbicide modes of action. 


\section{METHODS}

\section{Protein expression and purification}

Synthetic codon-optimised genes encoding AtDHDPR1 (At2G44040) and AtDHDPR2 (At3G59890), excluding the chloroplast transit peptides, cloned into the pET11a expression vector were purchased from Bioneer (Daejeon, South Korea). Plasmids were transformed into $E$. coli BL21 (DE3) cells, which were subsequently treated with $1.0 \mathrm{mM}$ IPTG to induce recombinant protein overexpression and cultured at $25 \square$ for $18 \mathrm{~h}$. Cells were harvested by centrifugation, resuspended in lysis buffer $(20 \mathrm{mM}$ Tris- $\mathrm{HCl}, 20 \mathrm{mM}$ imidazole, $500 \mathrm{mM} \mathrm{NaCl}$, $\mathrm{pH}$ 8.0) and lysed by sonication. Following cell debris removal by centrifugation, soluble protein was applied to a His-Trap column and eluted over a stepwise gradient of imidazole (0$500 \mathrm{mM}) .{ }^{35}$ Human rhinovirus $3 \mathrm{C}$ protease and $0.5 \mathrm{mM}$ TCEP were added to protein-containing fractions and incubated at room temperature for $1 \mathrm{~h}$ for fusion tag cleavage. The protein mixture was applied to a His-Trap column for removal of the protease and the cleaved tag before dialysing into storage buffer $(20 \mathrm{mM}$ Tris- $\mathrm{HCl}, 150 \mathrm{mM} \mathrm{NaCl}, \mathrm{pH} 8.0)$ and adding $0.5 \mathrm{mM}$ TCEP.

\section{Circular dichroism spectroscopy}

Spectra were collected using a CD spectrometer Model 420 (Aviv Biomedical) as described previously. ${ }^{36,37}$ AtDHDPR proteins in $20 \mathrm{mM} \mathrm{NaH}{ }_{2} \mathrm{PO}_{4}, 50 \mathrm{mM} \mathrm{KF}, \mathrm{pH} 8.0$ were diluted to $0.15 \mathrm{mg} \cdot \mathrm{mL}^{-1}$. Wavelength scans were performed between 195 and $260 \mathrm{~nm}$ with a slit band width of $1.0 \mathrm{~nm}$, step size of $0.5 \mathrm{~nm}$ and $5.0 \mathrm{~s}$ signal averaging time in a $1.0 \mathrm{~mm}$ quartz cuvette. The CDPro software package was used to fit the data to the SP22X reference set. ${ }^{38}$

\section{Enzyme kinetics and inhibition assays}

The DHDPS-DHDPR coupled assay was used to measure DHDPR enzyme activity, using methods similar to those described previously. ${ }^{22,23}$ Briefly, reaction mixtures were incubated at $30{ }^{\circ} \mathrm{C}$ for $12 \mathrm{~min}$ before a second $60 \mathrm{~s}$ incubation following the addition of excess E. coli DHDPS $\left(51 \mu \mathrm{g} \cdot \mathrm{mL}^{-1}\right)$ for generation of the DHDP substrate. Assays were then initiated by the addition of the relevant DHDPR isoform $\left(2.6 \mu \mathrm{g} \cdot \mathrm{mL}^{-1}\right)$, and substrate turnover measured spectrophotometrically at $340 \mathrm{~nm}$ via the associated oxidation of the cofactor NADPH. For determination of kinetic parameters, data were fit to a substrate inhibition model (Equation 1). 
For determination of $I C_{50}$ values, DHDPR activity was measured in the presence of titrated concentrations of inhibitors in $1 \%(\mathrm{v} / \mathrm{v})$ DMSO and data were fit to a variable slope model (Equation 2). Experiments were performed in technical triplicates.

Equation 1: $Y=\frac{V_{\max } \times X}{K_{M}+X \times\left(1+\frac{X}{K_{i}}\right)}$

Where $Y=$ initial rate, $V_{\max }=$ maximal enzyme velocity, $X=$ concentration of substrate, $K_{\mathrm{M}}=$ Michaelis-Menten constant, $K_{\mathrm{i}}=$ dissociation constant for substrate binding.

Equation 2: $Y=\frac{\text { Bottom }+(100-\text { Bottom })}{1+10^{\left.\left(\left(\log I C_{50}-X\right) \times \text { Hill Slope }\right)\right)}}$

Where $Y=$ response, Bottom $=$ plateau in the same units as $Y$, Hill slope $=$ slope factor.

\section{Crystallisation and structure determination}

Protein crystallisation screening for AtDHDPR1 was initially performed at the CSIRO Collaborative Crystallisation Centre (CSIRO, Parkville, Melbourne, Australia) using the sitting drop vapour diffusion method and Shotgun crystal screen at $8{ }^{\circ} \mathrm{C}$ and $20{ }^{\circ} \mathrm{C}$. Conditions were optimised in-house using the hanging drop vapour diffusion method and $4 \mu \mathrm{L}$ drops comprised of $2 \mu \mathrm{L}$ protein solution (10 $\mathrm{mg} \cdot \mathrm{mL}^{-1}$ AtDHDPR $\left.1,2 \mathrm{mM} \mathrm{NADPH}\right)$ and $2 \mu \mathrm{L}$ reservoir solution. Crystals used for data collection were obtained after 2 days at $20{ }^{\circ} \mathrm{C}$ using reservoir solutions containing 0.1 M bis-tris hydrochloride ( $\mathrm{pH}$ 6.5), 0.245 M magnesium formate, $22 \%(\mathrm{w} / \mathrm{v})$ PEG 3350. Crystals were transferred to cryo-protectant ( $0.1 \mathrm{M}$ bis-tris hydrochloride ( $\mathrm{pH} 6.5), 0.245$ M magnesium formate, 22\% (w/v) PEG 3350, 24\% (v/v) glycerol) and flash-frozen in liquid nitrogen. X-ray diffraction data were collected on the MX2 beamline at the Australian Synchrotron. ${ }^{39}$ Data were processed using XDS and scaled using AIMLESS and structure solved by molecular replacement using Auto-Rickshaw employing the EcDHDPR structure (PDB ID: 1ARZ) as a search model. ${ }^{40-43}$ Model refinement and building was conducted in PHENIX and COOT respectively. ${ }^{44,45}$ Model quality was evaluated using MOLPROBITY. ${ }^{46}$ The structure has been deposited in the Protein Data Bank with code 7T34. Data collection and refinement statistics are presented in Table 1. 


\section{Analytical ultracentrifugation}

Sedimentation velocity experiments were performed in a Beckman Coulter XL-A analytical ultracentrifuge at $25{ }^{\circ} \mathrm{C}$ using methods similar to those described previously. ${ }^{47-50}$ Briefly, $380 \mu \mathrm{L}$ of protein storage buffer containing $0.5 \mathrm{mM}$ TCEP, and $400 \mu \mathrm{L}$ of protein at $0.9 \mathrm{mg} \cdot \mathrm{mL}^{-1}$ were loaded into double sector cells with synthetic quartz windows. Centrifugation of cells was performed at 40,000 rpm using a 4-hole An50-Ti rotor. Data were collected continuously without averaging at $280 \mathrm{~nm}$ with a radial step size of $0.003 \mathrm{~cm}$. SEDNTERP software was used to compute solvent density $\left(1.007 \mathrm{~g} \cdot \mathrm{mL}^{-1}\right)$, solvent viscosity $(0.010259 \mathrm{cp})$ and estimated protein partial specific volume $\left(0.738218 \mathrm{~mL} \cdot \mathrm{g}^{-1}\right) .{ }^{51}$ SEDFIT was used to fit absorbance as a function of radial position to the Lamm equation to determine the continuous sedimentation coefficient distribution. ${ }^{51,52}$

\section{Growth inhibition assays on media}

A. thaliana ecotype Columbia (Col-0) seeds were surface sterilised for 5 min in $80 \%$ (v/v) EtOH, followed by $15 \mathrm{~min}$ in $1 \%$ (v/v) $\mathrm{NaClO}$ and then thorough washing in sterile $\mathrm{H}_{2} \mathrm{O}$. Seeds were resuspended in sterile $0.1 \%$ (w/v) plant tissue culture grade agar before stratification at $4 \square$ in the dark for 3 days. Seeds were sown on $0.25 \mathrm{~mL}$ of growth medium $(0.8 \%$ (w/v) agar, $1 \%(\mathrm{w} / \mathrm{v})$ sucrose, $0.44 \%$ (w/v) Murashige \& Skoog salts with vitamins, $2.5 \mathrm{mM} 2$ 2-(N-morpholino)ethanesulfonic acid (MES), pH 5.7) containing either DMSO (vehicle control) or inhibitor in 96well microplates, which were then sealed with porous tape. Plates were transferred to a chamber at $22 \square$ under a $16 \mathrm{~h}$ light $\left(100 \mu \mathrm{mol} \mathrm{m} \mathrm{m}^{-2} \mathrm{~s}^{-1}\right) / 8 \mathrm{~h}$ dark schedule for 7 days before photos were taken. Quantification of A. thaliana growth inhibition was performed as described previously, and the data were fit to a variable slope model (Equation 2) to determine the $\mathrm{LD}_{50}{ }^{26}$ Experiments were performed in technical triplicates.

\section{Antibacterial assays}

Minimum inhibitory concentration (MIC) values were determined using a broth microdilution assay in accordance with the guidelines issued by the Clinical Laboratory Standard Institute. ${ }^{53,54}$ Serial dilutions of 2,6-PDC were prepared in 96-well microplates using tryptic soy broth as the diluent. ${ }^{55,56}$ Plates were inoculated with $1 \times 10^{5}$ colony forming units per $\mathrm{mL}$ of bacteria and incubated at $25 \square$ for $20 \mathrm{~h}$. Growth was assessed by measuring the absorbance at $600 \mathrm{~nm}$ and the 
lowest concentration of inhibitor with no observable growth determined to be the MIC value. ${ }^{55,56}$ Experiments were performed in biological triplicates.

\section{Cell culture and cytotoxicity assays}

The human hepatocellular carcinoma (HepG2) cell line was grown and maintained in a humidified incubator at $37 \square$ with $5 \% \mathrm{CO}_{2}$ in high (HepG2) glucose Dulbecco's Modified Eagle's Medium (DMEM, Gibco, Waltham, USA, 11885084) with 10\% (v/v) fetal bovine serum (FBS, Gibco, 10099141) and $50 \mathrm{U} / \mathrm{mL}$ penicillin $/ 50 \mu \mathrm{g} \cdot \mathrm{mL}^{-1}$ streptomycin. Cytotoxicity assays were performed using similar methods to those previously described. ${ }^{7,57}$ Specifically, 5,000 viable cells/well were seeded into 96-well plates and incubated at $37 \square$ for $24 \mathrm{~h}$. Cells were subsequently treated with varying concentrations of inhibitor, 1\% (v/v) DMSO or the cytotoxic defensin protein $\mathrm{NaD} 1$ at $30 \mu \mathrm{M}$ and incubated at $37 \square .^{57,58}$ After $48 \mathrm{~h}$, cells were incubated with $0.5 \mathrm{mg} \cdot \mathrm{mL}^{-1}$ [3-(4,5-dimethylthiazolyl)-2,5-diphenyl-tetrazolium bromide] in DMEM without FBS at $37 \square$ for $3 \mathrm{~h}$. All liquid was removed from wells and formazan crystals dissolved in DMSO before measuring the absorbance at $570 \mathrm{~nm}$. The percentage viability remaining reported is relative to the $1 \%(\mathrm{v} / \mathrm{v})$ DMSO vehicle control. Four technical replicates were performed for each treatment condition.

\section{Herbicidal activity analyses}

The herbicidal efficacy of AtDHDPR inhibitors in soil was assessed using methods similar to those reported previously. ${ }^{34,59}$ Pre-wet seed-raising soil (pH 5.5) (Biogro, Dandenong South, VIC, Australia) supplemented with 0.22\% (w/w) Nutricote N12 Micro 140 day-controlled release fertiliser (Yates, Sydney, NSW, Australia) was used for all experiments. For experiments conducted with A. thaliana, approximately 40 ecotype Columbia (Col-0) seeds were sown in pots onto the soil surface following surface sterilisation and stratification as described for germination assays on media. For experiments conducted with L. rigidum, 10 seeds were sown at a depth of $0.5 \mathrm{~cm}$ into pots of pre-wet soil, following stratification at $4 \square$ for 21 days in the dark. Compounds dissolved in DMSO were diluted to working concentrations in $\mathrm{H}_{2} \mathrm{O}$ containing $0.01 \%(\mathrm{v} / \mathrm{v})$ Agral (Syngenta, North Ryde, NSW, Australia) to a final DMSO concentration of $2 \%(\mathrm{v} / \mathrm{v})$. Treatments were given by pipetting $1.0 \mathrm{~mL}$ (A. thaliana) or $2.0 \mathrm{~mL}$ (L. rigidum) of test compound, vehicle control or positive control (chlorosulfuron PESTANAL ${ }^{\circledR}$ (Sigma-Aldrich, 
North Ryde, NSW, Australia)) directly onto seeds upon sowing and on each of the subsequent two days. Plants were grown in a chamber at $22 \square$ under a $16 \mathrm{~h}$ light $\left(100 \mu \mathrm{mol} \mathrm{m} \mathrm{m}^{-2}\right) / 8 \mathrm{~h}$ dark schedule for 14 days before photos were taken. Roots and shoots were separated prior to drying at $70 \square$ for $72 \mathrm{~h}$. Experiments were performed in biological triplicates.

\section{Supplementary Information}

Supplementary Figure S1. Expression and purification of recombinant AtDHDPR enzymes.

Supplementary Figure S2. Secondary structure of AtDHDPR isoforms.

Supplementary Figure S3. Sedimentation velocity analysis by analytical ultracentrifugation of AtDHDPR1.

Supplementary Figure S4. Viability of human cells treated with 2,6-PDC. Supplementary Figure S5. Sequence alignment of plant DHDPR enzymes.

Supplementary Table S1. Minimum inhibitory concentration (MIC) values of 2,6-PDC against soil bacteria.

Supplementary Table S2. Maximal expression levels of $A$. thaliana DHDPR isoforms and commercial herbicide targets determined by RNA-sequencing.

Supplementary Table S3. Physicochemical properties of lead compounds.

Supplementary Methods S1. Synthesis of compounds.

Supplementary Data S1. NMR spectra of compounds.

\section{ACKNOWLEDGEMENTS}

T.P.S.C. acknowledges the Australian Research Council for funding support through a DECRA Fellowship (DE190100806). Work in A.R.G.'s laboratory is supported by the Australian Research Council Research Hub for Medicinal Agriculture (IH180100006). E.R.R.M. acknowledges the Grains Research and Development Corporation (9176977) for support through a $\mathrm{PhD}$ scholarship and operational funding and La Trobe University for support through a Research Training Program scholarship. We thank Professor Ashley Franks (La Trobe University, Australia) for supplying bacterial isolates and Professor John Moses (La Trobe University, Australia) for providing infrastructure. We acknowledge the La Trobe University Comprehensive Proteomics Platform for providing infrastructure support. We acknowledge the 
bioRxiv preprint doi: https://doi.org/10.1101/2022.02.20.481218; this version posted February 21, 2022. The copyright holder for this preprint (which was not certified by peer review) is the author/funder, who has granted bioRxiv a license to display the preprint in perpetuity. It is made available under aCC-BY-NC-ND 4.0 International license.

use of the MX2 beamline at the Australian Synchrotron, part of ANSTO and employed the Australian Cancer Research Foundation (ACRF) detector. 


\section{AUTHOR CONTRIBUTIONS}

E.R.R.M. performed the biology experiments, analysed data and co-wrote the manuscript. A.S.B. synthesised compounds, analysed data and co-wrote the manuscript. M.-C.G. synthesised compounds and analysed data. M.D.H. and A.R.G. provided reagents and materials and revised the manuscript. S.P. analysed data and revised the manuscript. T.P.S.C. designed the research and co-wrote the manuscript.

\section{COMPETING INTERESTS}

The authors declare no competing interests. 


\section{REFERENCES}

1. Gianessi, L. P. The increasing importance of herbicides in worldwide crop production. Pest Manag. Sci. 69, 1099-1105 (2013).

2. Heap, I. The International Herbicide-Resistant Weed Database. http://www.weedscience.org/Home.aspx (2020).

3. Duke, S. O. Why have no new herbicide modes of action appeared in recent years? Pest Manag. Sci. 68, 505-512 (2011).

4. Hall, C. J., Mackie, E. R. R., Gendall, A. R., Perugini, M. A. \& Soares da Costa, T. P. Review: amino acid biosynthesis as a target for herbicide development. Pest Manag. Sci. 76, 3896-3904 (2020).

5. Hildebrandt, T. M., Nunes Nesi, A., Araújo, W. L. \& Braun, H. P. Amino acid catabolism in plants. Mol. Plant 8, 1563-1579 (2015).

6. Hall, C. J. \& Soares Da Costa, T. P. Lysine: biosynthesis, catabolism and roles. WikiJournal Sci. 1, 4 (2018).

7. Soares da Costa, T. P. et al. Towards novel herbicide modes of action by inhibiting lysine biosynthesis in plants. Elife 10, 1-17 (2021).

8. Hall, C. J. et al. Differential lysine-mediated allosteric regulation of plant dihydrodipicolinate synthase isoforms. FEBS J. 288, 4973-4986 (2021).

9. Soares da Costa, T. P., Abbott, B. M., Gendall, A. R., Panjikar, S. \& Perugini, M. A. Molecular evolution of an oligomeric biocatalyst functioning in lysine biosynthesis. Biophys. Rev. 10, 153-162 (2018).

10. Paiva, A. M. et al. Inhibitors of dihydrodipicolinate reductase, a key enzyme of the diaminopimelate pathway of Mycobacterium tuberculosis. Biochim. Biophys. Acta Protein Struct. Mol. Enzymol. 1545, 67-77 (2001).

11. Hutton, C. A., Perugini, M. A. \& Gerrard, J. A. Inhibition of lysine biosynthesis $\square$ : an evolving antibiotic strategy. Mol. Biosyst. 3, 458-465 (2007).

12. Fazius, F., Zaehle, C. \& Brock, M. Lysine biosynthesis in microbes: relevance as drug 
target and prospects for $\beta$-lactam antibiotics production. Appl. Microbiol. Biotechnol. 97, 3763-3772 (2013).

13. Ray, S. S. et al. Cocrystal structures of diaminopimelate decarboxylase: mechanism, evolution, and inhibition of an antibiotic resistance accessory factor. Structure 10, 14991508 (2002).

14. Cox, R. J., Sherwin, W. A., Lam, L. K. P. \& Vederas, J. C. Synthesis and evaluation of novel substrates and inhibitors of N-succinyl-LL-diaminopimelate aminotransferase (DAP-AT) from Escherichia coli. J. Am. Chem. Soc. 118, 7449-7460 (1996).

15. Mitsakos, V. et al. Inhibiting dihydrodipicolinate synthase across species: Towards specificity for pathogens? Bioorg. Med. Chem. Lett. 18, 842-844 (2008).

16. Soares Da Costa, T. P. et al. Structural Determinants Defining the Allosteric Inhibition of an Essential Antibiotic Target. Struct. Des. 24, 1282-1291 (2016).

17. Watkin, S. A. J. et al. Plant DHDPR forms a dimer with unique secondary structure features that preclude higher-order assembly. Biochem. J. 475, 137-150 (2018).

18. Watanabe, N. et al. Crystal Structure of 1l-Diaminopimelate Aminotransferase from Arabidopsis thaliana: A Recently Discovered Enzyme in the Biosynthesis of 1-Lysine by Plants and Chlamydia. J. Mol. Biol. 371, 685-702 (2007).

19. Reddy, S. G., Sacchettini, J. C. \& Blanchard, J. S. Expression, Purification, and Characterization of Escherichia coli Dihydrodipicolinate Reductase. Biochemistry 34, 3492-3501 (1995).

20. Watkin, S. A. J. et al. Plant DHDPR forms a dimer with unique secondary structure features that preclude higher-order assembly. Biochem. J. 475, 137-150 (2018).

21. Dogovski, C., Dommaraju, S. R., Small, L. C. \& Perugini, M. A. Comparative structure and function analyses of native and his-tagged forms of dihydrodipicolinate reductase from methicillin-resistant Staphylococcus aureus. Protein Expr. Purif. 85, 66-76 (2012).

22. Christensen, J. B. et al. Structure and Function of Cyanobacterial DHDPS and DHDPR. Sci. Rep. 6, 1-12 (2016). 
23. Coulter, C. V, Gerrard, J. A., Kraunsoe, J. A. E. \& Pratt, A. J. Escherichia coli dihydrodipicolinate synthase and dihydrodipicolinate reductase: kinetic and inhibition studies of two putative herbicide targets. Pestic. Sci. 55, 887-895 (1999).

24. Griffin, M. D. W. et al. Characterisation of the first enzymes committed to lysine biosynthesis in Arabidopsis thaliana. PLoS One 7, 1-12 (2012).

25. Scapin, G., Reddy, S. G., Zheng, R. \& Blanchard, J. S. Three-Dimensional Structure of Escherichia coli Dihydrodipicolinate Reductase in Complex with NADH and the Inhibitor 2,6-Pyridinedicarboxylate. Biochemistry 36, 15081-15088 (1997).

26. Corral, M. G., Leroux, J., Stubbs, K. A. \& Mylne, J. S. Herbicidal properties of antimalarial drugs. Sci. Rep. 7, 45871 (2017).

27. Klepikova, A. V., Kasianov, A. S., Gerasimov, E. S., Logacheva, M. D. \& Penin, A. A. A high resolution map of the Arabidopsis thaliana developmental transcriptome based on RNA-seq profiling. Plant J. 88, 1058-1070 (2016).

28. Christoff, R. M., Gardhi, C. K., Costa, T. P. S. da, Perugini, M. A. \& Abbott, B. M. Pursuing DHDPS: an enzyme of unrealised potential as a novel antibacterial target. Med. Chem. Commun. 10, 1581-1588 (2019).

29. Tieu, W. et al. Improved Synthesis of Biotinol-5'-AMP: Implications for Antibacterial Discovery. ACS Med. Chem. Lett. 6, 216-220 (2015).

30. Impey, R. E., Hawkins, D. A., Sutton, M. J. \& Soares da Costa, T. P. Overcoming Intrinsic and Acquired Resistance Mechanisms Associated with the Cell Wall of GramNegative Bacteria. Antibiotics 9, 1-19 (2020).

31. Gupta, R., Hogan, C. J., Perugini, M. A. \& Soares da Costa, T. P. Characterization of recombinant dihydrodipicolinate synthase from the bread wheat Triticum aestivum. Planta 248, 381-391 (2018).

32. Cha, Y. et al. Drug repurposing from the perspective of pharmaceutical companies. Br. $J$. Pharmacol. 175, 168-180 (2018).

33. Evans-Roberts, K. M. et al. DNA gyrase is the target for the quinolone drug ciprofloxacin 
in arabidopsis thaliana. J. Biol. Chem. 291, 3136-3144 (2016).

34. Corral, M. G. et al. Exploiting the Evolutionary Relationship between Malarial Parasites and Plants To Develop New Herbicides. Angew. Chemie Int. Ed. 56, 9881-9885 (2017).

35. Gupta, R., Soares da Costa, T. P., Faou, P., Dogovski, C. \& Perugini, M. A. Comparison of untagged and his-tagged dihydrodipicolinate synthase from the enteric pathogen Vibrio cholerae. Protein Expr. Purif. 145, 85-93 (2018).

36. Greenfield, N. J. Using circular dichroism spectra to estimate protein secondary structure. Nat. Protoc. 1, 2876-2890 (2007).

37. Impey, R. E. et al. Identification of two dihydrodipicolinate synthase isoforms from Pseudomonas aeruginosa that differ in allosteric regulation. FEBS J. 287, 386-400 (2020).

38. Sreerama, N. \& Woody, R. W. Computation and Analysis of Protein Circular Dichroism Spectra. Methods Enzymol. 383, 318-351 (2004).

39. Aragão, D. et al. MX2: a high-flux undulator microfocus beamline serving both the chemical and macromolecular crystallography communities at the Australian Synchrotron. J. Synchrotron Radiat. 25, 885-891 (2018).

40. Kabsch, W. XDS. Acta Crystallogr. Sect. D Struct. Biol. 66, 125-132 (2010).

41. Collaborative Computational Project, N. 4. The CCP4 suite: programs for protein crystallography. Acta Crystallogr. Sect. D Struct. Biol. 50, 760-763 (1994).

42. Panjikar, S., Parthasarathy, V., Lamzin, V. S., Weiss, M. S. \& Tucker, P. A. AutoRickshaw: an automated crystal structure determination platform as an efficient tool for the validation of an X-ray diffraction experiment. Acta Crystallogr. Sect. D Struct. Biol. 61, 449-457 (2005).

43. Panjikar, S., Parthasarathy, V., Lamzin, V. S., Weiss, M. S. \& Tucker, P. A. On the combination of molecular replacement and single-wavelength anomalous diffraction phasing for automated structure determination. Acta Crystallogr. Sect. D Biol. Crystallogr. 65, 1089-1097 (2009). 
44. Echols, N. et al. Automating crystallographic structure solution and refinement of proteinligand complexes. Acta Crystallogr. Sect. D Biol. Crystallogr. 70, 144-154 (2014).

45. Emsley, P., Lohkamp, B., Scott, W. G. \& Cowtan, K. Features and development of Coot. Acta Crystallogr. D. Biol. Crystallogr. 66, 486-501 (2010).

46. Williams, C. J. et al. MolProbity: More and better reference data for improved all-atom structure validation. Protein Sci. 27, 293-315 (2018).

47. Soares da Costa, T. P. et al. Identification of a dimeric KDG aldolase from Agrobacterium tumefaciens. Proteins 85, 2058-2065 (2017).

48. Soares da Costa, T. P. et al. Dual roles of F123 in protein homodimerization and inhibitor binding to biotin protein ligase from Staphylococcus aureus. Mol. Microbiol. 91, 110-120 (2014).

49. Soares da Costa, T. P. et al. Quaternary Structure Analyses of an Essential Oligomeric Enzyme. Methods Enzymol. 562, 205-223 (2015).

50. Sakthivel, D. et al. The oligomeric assembly of galectin-11 is critical for anti-parasitic activity in sheep (Ovis aries). Commun. Biol. 3, 1-8 (2020).

51. Laue, T. Biophysical studies by ultracentrifugation. Curr. Opin. Struct. Biol. 11, 579-583 (2001).

52. Schuck, P., Perugini, M. A., Gonzales, N. R., Hewlett, G. J. \& Schubert, D. Sizedistribution analysis of proteins by analytical ultracentrifugation: Strategies and application to model systems. Biophys. J. 82, 1096-1111 (2002).

53. National Committee for Clinical Laboratory Standards, Wayne, P. Methods for dilution antimicrobial susceptibility tests for bacteria that grow aerobically, 6th ed. Approved standard. NCCLS publication no. M7-A6.

54. National Committee for Clinical Laboratory Standard, Wayne, P. Standard for antimicrobial susceptibility testing, 13th informational supplement.. NCCLS publication no. M100-S14.

55. Giel, M. $\square$ C et al. Metal $\square$ Free Synthesis of Functional $1 \square$ Substituted $\square 1,2,3 \square$ Triazoles 
from Ethenesulfonyl Fluoride and Organic Azides. Angew. Chemie Int. Ed. 59, 1181-1186 (2020).

56. Li, Z. et al. Synthesis, conformational analysis and antibacterial activity of $\mathrm{Au}(\mathrm{I})-\mathrm{Ag}(\mathrm{I})$ and $\mathrm{Au}(\mathrm{I})-\mathrm{Hg}(\mathrm{II})$ heterobimetallic N-heterocyclic carbene complexes. Dalt. Trans. 49, 12820-12834 (2020).

57. Soares Da Costa, T. P. et al. Selective inhibition of biotin protein ligase from Staphylococcus aureus. J. Biol. Chem. 287, 17823-17832 (2012).

58. Baxter, A. A., Poon, I. K. \& Hulett, M. D. The plant defensin NaD1 induces tumor cell death via a non-apoptotic, membranolytic process. Cell Death Discov. 3, 1-11 (2017).

59. Corral, M. G. et al. A herbicide structure-activity analysis of the antimalarial lead compound MMV007978 against Arabidopsis thaliana. Pest Manag. Sci. 74, 1558-1563 (2018). 


\section{FIGURES}

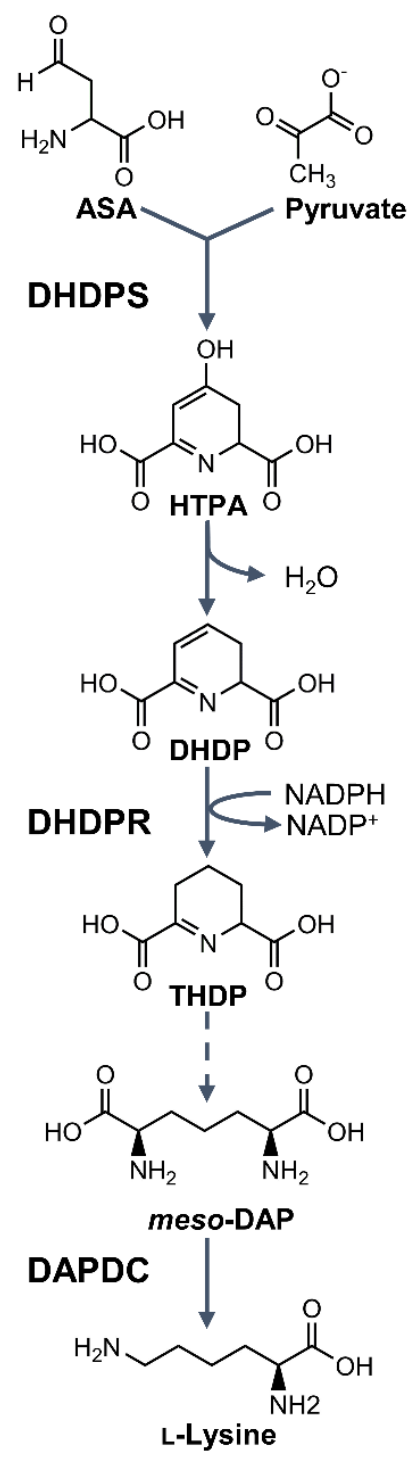

Figure 1. The diaminopimelate (DAP) pathway. The dihydrodipicolinate synthase (DHDPS)catalysed condensation of aspartate semialdehyde (ASA) and pyruvate yields 4-hydroxy-2,3,4,5tetrahydro-dipicolinic acid (HTPA), which is non-enzymatically dehydrated to form dihydrodipicolinate (DHDP). The NADPH-dependent reduction of DHDP to yield 2,3,4,5tetrahydrodipicolinate (THDP) is catalysed by dihydrodipicolinate reductase (DHDPR). mesoDAP is eventually produced via one of four species-dependent sub-pathways, which is decarboxylated by DAP decarboxylase (DAPDC) to form L-lysine. 
A

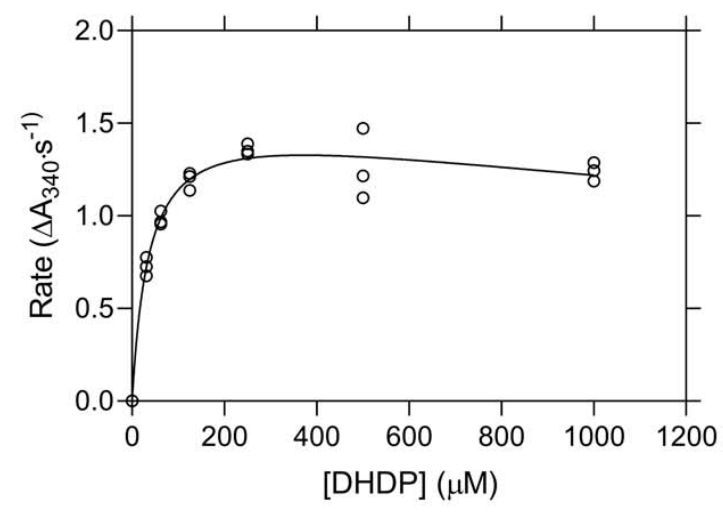

B

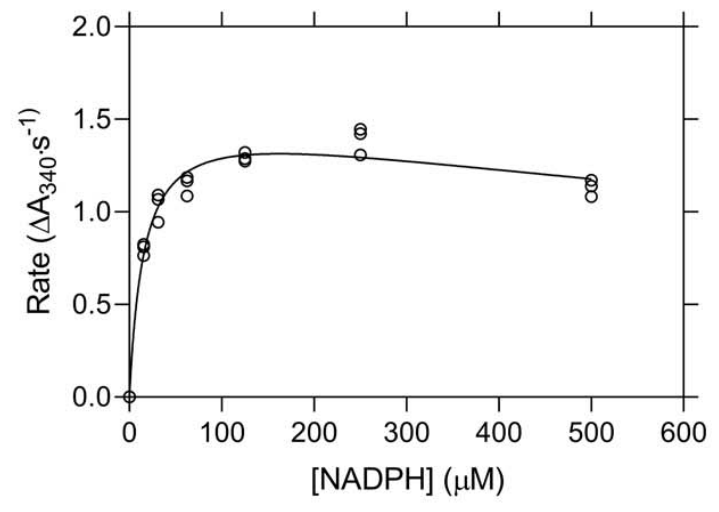

Figure 2. Kinetic analyses of Arabidopsis thaliana (At) DHDPR1. Initial rate (O) plotted as a function of (A) DHDP or (B) NADPH concentration. The nonlinear best fits (-) were obtained to a substrate inhibition model resulting in $\mathrm{R}^{2}$ values of 0.97 and 0.96 , respectively. $n=3$. 


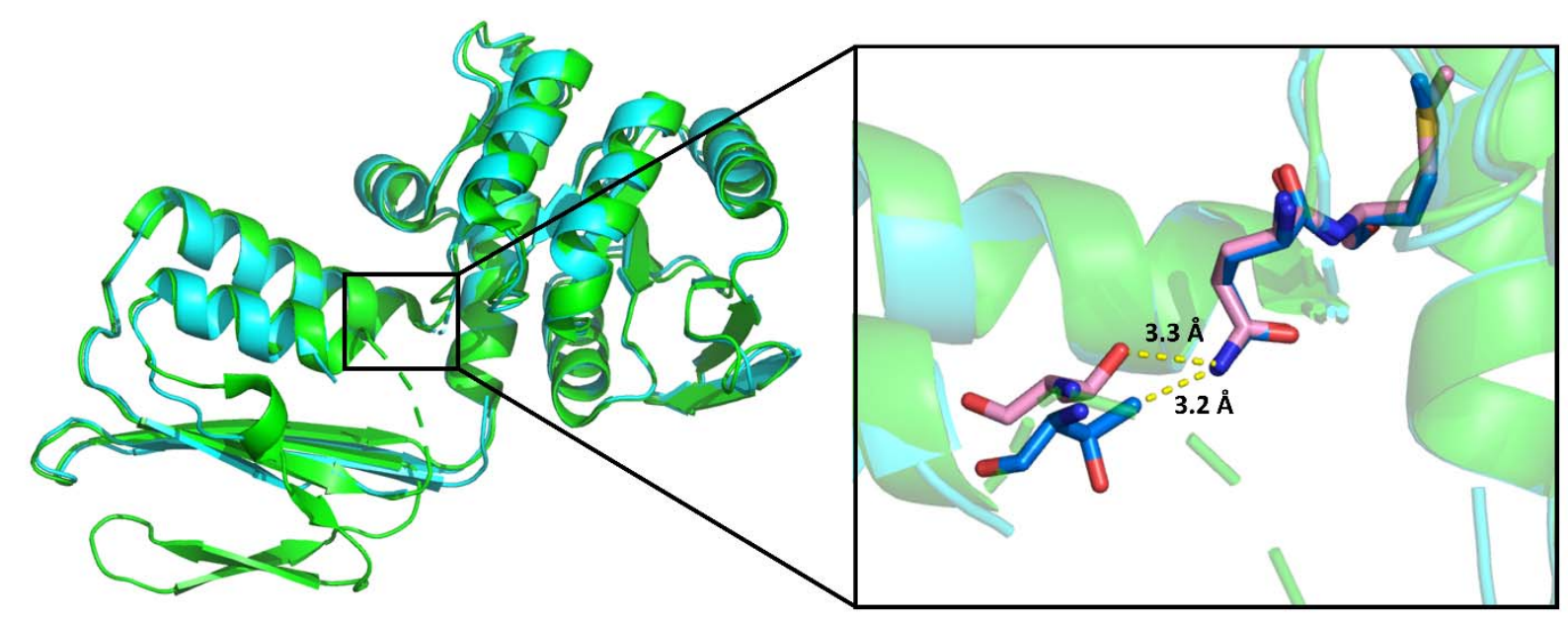

Figure 3. Structural alignment of AtDHDPR1 and AtDHDPR2. The monomeric crystal structure of AtDHDPR1 (cyan, PDB ID: 7T34) aligned with chain C of the dimeric AtDHDPR2 crystal structure (green, PDB ID: 5UA0). The inset depicts the proximity of the conserved 'latch and catch' residues of AtDHDPR1 (blue) and AtDHDPR2 (pink) allowing for hydrogen bonding, which stabilises the enzyme's closed conformation. 
A

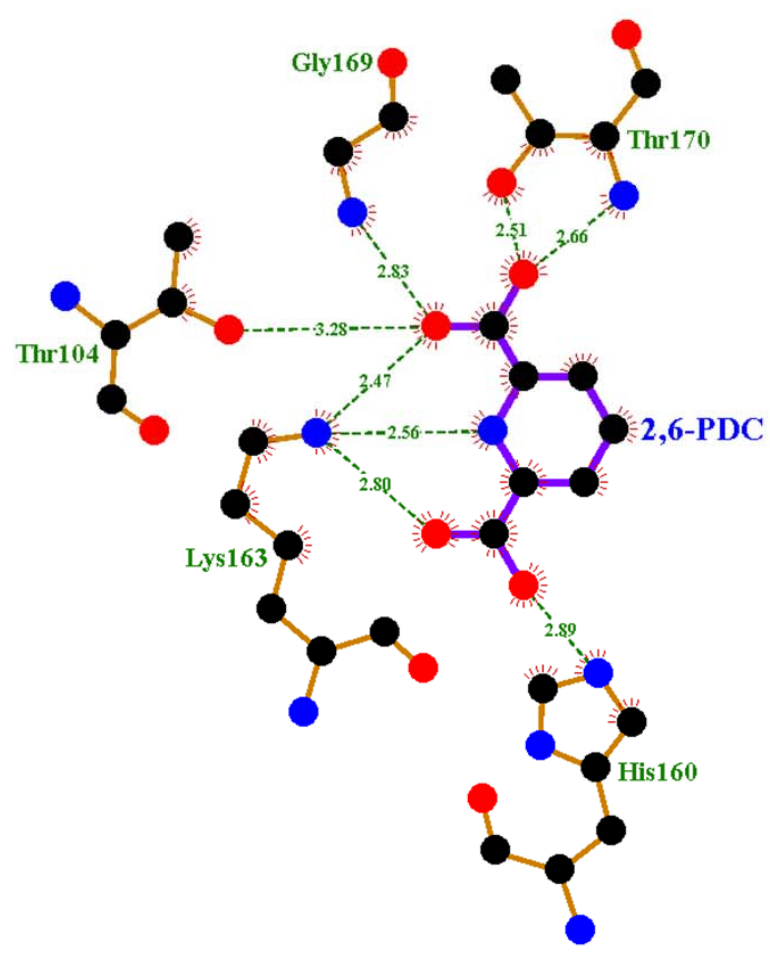

B
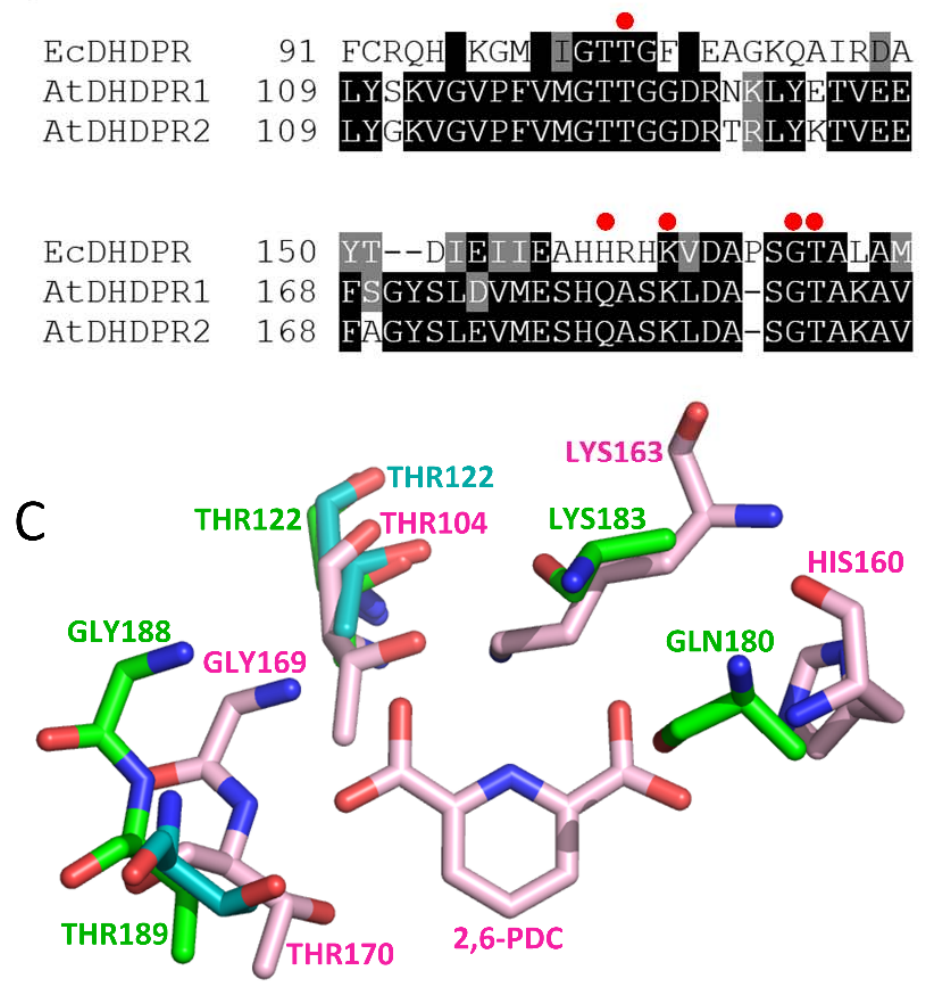

Figure 4. Homology of the 2,6-PDC binding pocket. (A) Schematic diagram of the 2,6pyridine dicarboxylic acid (2,6-PDC) binding site in the three-dimensional structure of Escherichia coli DHDPR generated using LIGPLOT+. (B) Primary sequence alignment of DHDPR from E. coli (Ec) and Arabidopsis thaliana (At) generated using CLUSTALW. Residues forming hydrogen bonds with 2,6-PDC are indicated by red dots. (C) Overlay of the

2,6-PDC-bound site binding pocket 1ARZ) with that of PDB ID: 7T34) and PDB ID: 5UA0).
A

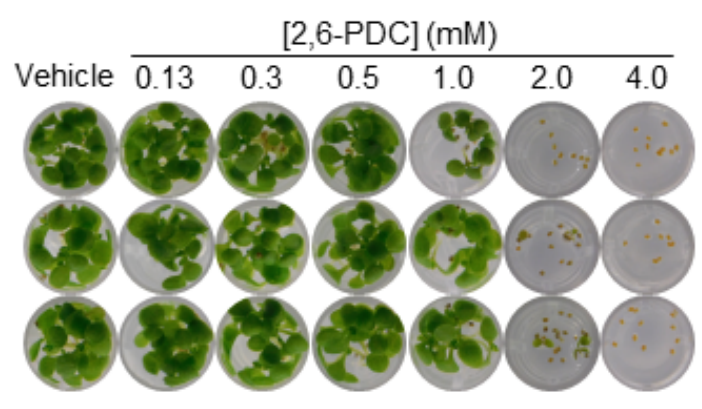

B

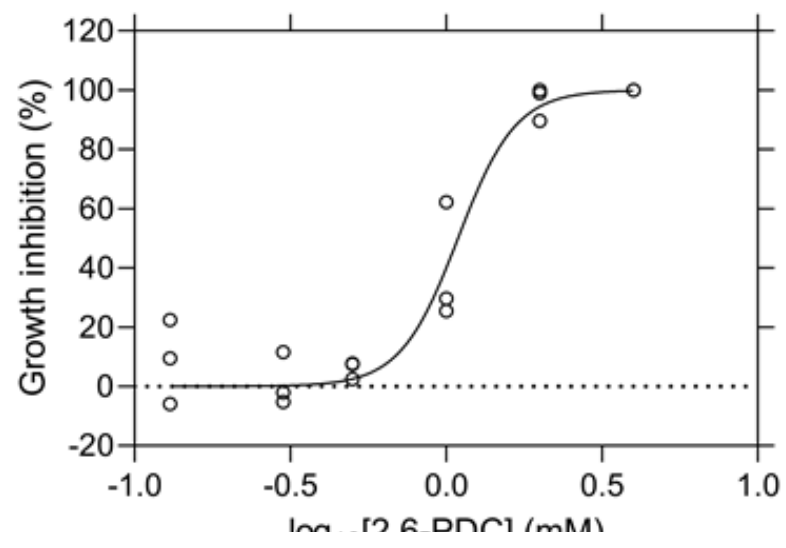

EcDHDPR active (pink, PDB ID: AtDHDPR1 (cyan, AtDHDPR2 (green, 

available under aCC-BY-NC-ND 4.0 International license.

Figure 5. Growth of $\boldsymbol{A}$. thaliana on media containing 2,6-PDC. (A) A. thaliana seeds raised on agar containing a concentration gradient of 2,6-PDC. (B) Dose-response curve for 2,6-PDC. The percentage of growth inhibition $(\circ)$ relative to the DMSO control is plotted as a function of 2,6-PDC concentration. Data were fit to a variable slope model (-) resulting in an $\mathrm{R}^{2}$ value of 0.95. $n=3$.
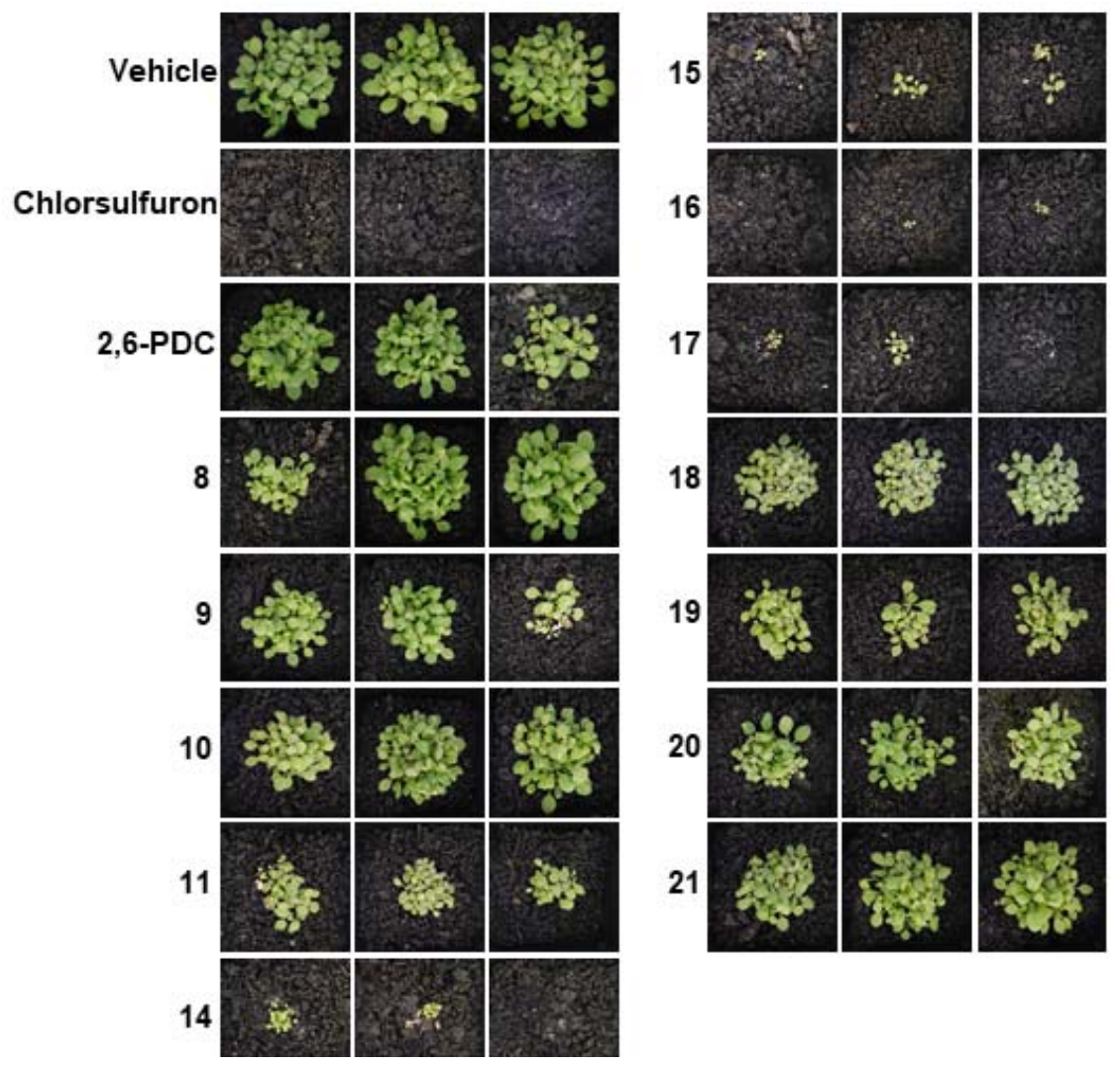
bioRxiv preprint doi: https://doi.org/10.1101/2022.02.20.481218; this version posted February 21, 2022. The copyright holder for this preprint

(which was not certified by peer review) is the author/funder, who has granted bioRxiv a license to display the preprint in perpetuity. It is made available under aCC-BY-NC-ND 4.0 International license.

Figure 6. Herbicidal activity of 2,6-PDC analogues against A. thaliana. 14-day growth of A. thaliana treated with $1200 \mathrm{mg} \cdot \mathrm{L}^{-1}$ of 2,6 -PDC analogues. Images show the three replicates performed for each inhibitor. 

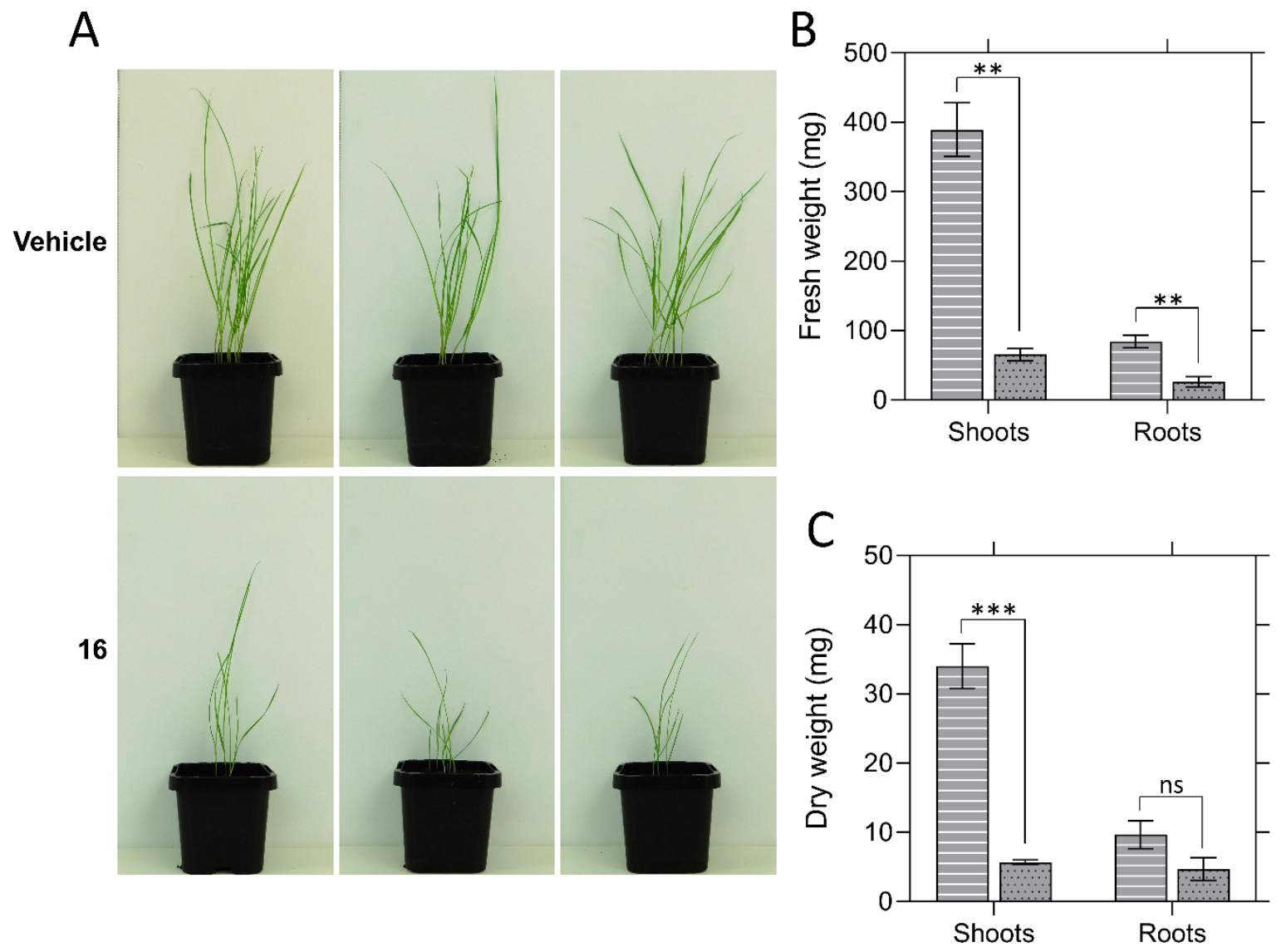

Figure 7. Growth of Lolium rigidum treated with 16. (A) 14-day growth of L. rigidum treated with three pre-emergence treatments of vehicle control $(2 \%(\mathrm{v} / \mathrm{v})$ DMSO, $0.01 \%$ Agral) or $1200 \mathrm{mg} \cdot \mathrm{L}^{-1}$ of 16. Images show the three replicates performed. (B) Fresh weight of L. rigidum shoots and roots following treatment of plants with vehicle control (lines) or $1200 \mathrm{mg} \cdot \mathrm{L}^{-1}$ of 16 (dots). Shoots, $P=0.0013$, roots, $P=0.0076$, unpaired Student's two-tailed $t$-test. (C) Dry weight of $L$. rigidum shoots and roots following treatment of plants with vehicle control (lines) or $1200 \mathrm{mg} \cdot \mathrm{L}^{-1}$ of 16 (dots). Shoots, $P=0.0009$, roots, $P=0.1295$, unpaired Student's two-tailed $t$-test. Data were normalised against the vehicle control. Data represents mean \pm S.E.M. $(N=3)$. $* * P<0.01, * * * P<0.001$. 


\section{TABLES}

Table 1. Summary of AtDHDPR1 crystallographic data collection, processing and refinement statistics.

\section{Data collection}

Space group

Unit-cell parameters $(\AA)$

Resolution $(\AA)$

No. of observations

No. of unique reflections

Completeness (\%)

Redundancy

$R_{\text {merge }}(\%)$

$R_{\text {meas }}(\%)$

$\mathrm{CC}_{1 / 2}$

Average $\mathrm{I} / \sigma(\mathrm{I})$

Wilson-B

\section{Refinement}

$R(\%)$

$R_{\text {free }}(\%)$

No. (\%) of reflections in test set

No. of protein molecules per asu

r.m.s.d bond length $(\AA)$

r.m.s.d bond angle $\left(^{\circ}\right)$

Average B-factors $\left(\AA^{2}\right)$

Protein molecules

Ligand molecules

Water molecules

Ramachandran plot

Residues other than Gly and Pro in:

Most favoured regions (\%) 95

Additionally allowed regions (\%)

Disallowed regions (\%)

PDB code

\section{AtDHDPR1}

I $4{ }_{1} 22$

118.84, 118.84, 127.44, 90, 90, 90

$43.46-2.889(2.993-2.889)$

145103 (23331)

$11082(1740)$

$99.68(97.74)$

$13.09(13.41)$

$4.4(119.7)$

$4.6(124.4)$

$100(84.6)$

30.28 (1.79)

116

18.76

22.02

9.81

1

0.009

0.968

119.9

0

0 
Table 2. Growth of $A$. thaliana on media containing 2,6-PDC analogues at a concentration of 1 $\mathrm{mM}$ performed in triplicate.

\begin{tabular}{|c|c|c|c|c|c|}
\hline ID & $\mathrm{R}$ & ID & $\mathrm{R}$ & ID & $\mathrm{R}$ \\
\hline 2,6-PDC & $\mathrm{HO}$ & 8 & & 16 & \\
\hline 1 & & 9 & & 17 & \\
\hline 2 & & 10 & & 18 & \\
\hline 3 & & 11 & & 19 & \\
\hline 4 & & 12 & & 20 & \\
\hline 5 & & 13 & & 21 & $\mathrm{H}$ \\
\hline 6 & & 14 & & & \\
\hline 7 & & 15 & & & \\
\hline
\end{tabular}

